\title{
Metodologia para integração de uma rede de radares meteorológicos: aplicação para o estado de São Paulo
}

\author{
Methodology for the ingration of a weather radar network: application to the stape \\ of São Paulo
}

\author{
Carlos Augusto Morales e Wando Celso Amorim \\ Universidade de São Paulo, SP, Brasil \\ morales@model.iag.usp.br; wando.amorim_inpe@tvglobo.com.br
}

\begin{abstract}
RESUMO
Neste artigo são apresentados dois procedimentos para a integração de uma rede de radares meteorológicos que podem ser aplicados em outras redes. Neste estudo em particular aplica-se as metodologias para os radares meteorológicos do estado de São Paulo. A metodologia consiste inicialmente na calibração dos radares meteorológicos para uniformização das observações e posterior integração. A calibração dos radares foi feita a partir da comparação com medidas coincidentes do radar meteorológico a bordo do Tropical Rainfall Measuring Mission (TRMM). Nesta inter-comparação foi observado que os radares meteorológicos de Salesópolis e Presidente Prudente superestimavam o fator refletividade do radar em $+6,0$ e $+4,4$ dBZ respectivamente, enquanto que o radar de Bauru subestimava em -4,3 dBZ. Para a integração dos radares meteorológicos foi utilizado um método que utiliza os planos indicadores de posição a altitude constante (CAPPIs) e um outro que usa os dados volumétricos projetados em um espaço tridimensional. O método do CAPPI leva em consideração somente a distância do ponto ao radar, enquanto que no volumétrico a contribuição de cada volume iluminado que intercepta o volume da integração. Comparando os campos integrados e os observados individualmente pelos três radares, constatou-se que o método de CAPPIs apresenta uma superestimativa para valores inferiores a $29 \mathrm{dBZ}$ e subestimativa acima, enquanto que no procedimento volumétrico existe uma subestimativa quase que constante de $0,5 \mathrm{dBZ}$.
\end{abstract}

\begin{abstract}
This study presents two procedures to integrate three weather radars in the State of São Paulo that can be extended to any other radar network. The methology consists of a radar calibration procedure followed by the integratio. The radar calibration is based on the Tropical Rainfall Measuring Mission (TRMM) Precipitation Radar (PR) coincident measurements. In this procedure, it was found that both Salesópolis and Presidente Prudent weather radars were over-estimating the radar refletivity fator $(\mathrm{Z})$ by +6.0 and $+4.4 \mathrm{dBZ}$ respectively, while Bauru radar was under-estimating by $-4.3 \mathrm{dBZ}$. Upon the calibration, the 3 weather radars were integrated by employing the constant altitude plan position indicator (CAPPIs) and the iluminated volume projected in a 3D space. In the CAPPI procedure, only the distance from the radar was used to weight the measurements, while for the volumetric methodology we employed the contribution of the ilumilated volume fraction that intercepted the integrated volume. Based on these two approaches it was found that the CAPPI integration presented under estimation for $Z<29 \mathrm{dBZ}$ and super-estimation above, while the Volumetric method understimate almost constant at 0,5 dBZ.
\end{abstract}




\section{INTRODUÇÃO}

A partir da iniciativa pioneira do Instituto de Pesquisas Meteorológicas (IPMet) da Fundação Educadora de Bauru, a FAPESP financia a implantação do primeiro radar meteorológico do Brasil, que acabou instalado em 1974 na cidade de Bauru (SP). Este radar meteorológico Banda C operou entre 1974 e 1992 quando foi substituído por um radar meteorológico Doppler Banda S. Esta experiência e as recorrentes enchentes na região metropolitana de São Paulo, levaram ao Departamento de Águas e Energia Elétrica (DAEE) do estado de São Paulo em 1989 a instalar um radar meteorológico banda $\mathrm{S}$ na cidade de Salesópolis (SP), sendo que em 2014 este radar foi atualizado por um radar meteorológico Doppler Banda S de dupla polarização. Mais tarde, no final da década de 1990, outro radar meteorológico Doppler Banda S foi instalado em Presidente Prudente (SP) pelo IPMet/UNESP. Entretanto apesar do estado de São Paulo possuir 3 radares meteorológicos e sofrer constantemente com enchentes, inundações e deslizamentos, os mesmos nunca foram integrados $\mathrm{e}$ disponibilizados publicamente.

No Brasil, esta experiência se repete. Por exemplo, o Departamento do Controle do Espaço Aéreo (DECEA) do Brasil financiou o desenvolvimento de tecnologia nacional para a construção de radares meteorológicos Doppler Banda S durante a década de 1990. Ao longo de 1990 e 2000 seis radares foram instalados em Canguçu e Santiago (RS), Morro da Igreja (SC), São Roque (SP), Pico do Couto (RJ) e Gama (DF) até 2000. Mais tarde entre 2001-2002, o Sistema de Vigilância da Amazônia (SIPAM) finaliza a instalação de 10 radares meteorológicos Doppler Banda S na Amazônia Legal (São Gabriel da Cachoeira, Cruzeiro do Sul, Porto Velho, Tabatinga, Tefé, Manaus, Boa Vista, Santarém, Macapá e Belém) e em 2011 mais um em São Luiz (MA). Em 2010, um radar meteorológico Doppler banda X de Dupla Polarização é instalado na base de lançamento de Alcântara (CLA). Finalmente, ao longo de 2012 e 2014, Centro Nacional de Monitoramento e Alertas de Desastres Naturais (CEMADEN) instala 9 radares meteorológicos Doppler Banda $\mathrm{S}$ de
Dupla Polarização ao longo do litoral Brasileiro e centro oeste/sudeste Brasileiro (Natal (RN), Petrolina (PE), Maceió (AL), Salvador (BA), Almenara (MG), São Francisco (MG), Três Marias (MG), Santa Teresa (ES) e Jaraguari (MS)).

Concomitantemente, durante estes últimos 20 anos, diversas ações pontuais de institutos de pesquisa e ou operacional de meteorologia possibilitaram a instalação de mais radares no Brasil como, por exemplo: a) Fundação Cearense de Meteorologia (FUNCEME) instala o $1^{\circ}$ radar meteorológico Doppler Banda X em Fortaleza (CE) em 1993 e mais tarde em 2011 um radar Doppler Banda $\mathrm{S}$ em Quixeramobim (CE); b) Sistema Meteorológico do Paraná (SIMEPAR) instala 2 radares meteorológicos, sendo o primeiro em 1998 na cidade de Teixeira Soares (PR) um radar Doppler Banda S e o segundo em 2014 na cidade de Cascavel (PR) um radar meteorológico Doppler Banda $\mathrm{S}$ de Polarização circular; c) CEMIG instala um radar meteorológico Doppler Banda C de Dupla Polarização em Mateus Leme (MG); d) Vale do Espírito Santo e Centro Capixaba de Monitoramento Hidrológico instalam um radar meteorológico Doppler Banda S de Dupla Polarização em 2013 na cidade de Aracruz (ES); e) EPAGRI e CIRAM instalam em 2014 um radar meteorológico Doppler Banda S de Dupla Polarização em Lontras (SC). Além disso, radares meteorológicos móveis também foram utilizados em diversos experimentos de campo com o objetivo de caracterizar a chuva no Brasil. Dentre eles temos: a) Instituto de Estudos Avançados (IEA) do Centro Técnico Aeroespacial (CTA) instala um radar meteorológico Banda $\mathrm{C}$ em Petrolina (PE) durante o período o $1^{\circ}$ semestre de 1985 para estudar a precipitação no semiárido brasileiro; b) Entre 1985 e 1987 o Amazon Boundary Layer Exepriment -ABLE A e B instalou um radar meteorológico Banda $X$ para quantificar a extensão e propagação dos sistemas precipitantes na Amazônia ; c) Tropical Rainfall Measuring Mission (TRMM) e Large Scale Biosphere of Amazon (LBA) realizam medidas em Janeiro e Fevereiro de 1999 com dois radares meteorológicos instalados em Rondônia, sendo um Doppler Banda C e um outro 
Doppler Banda S de Dupla Polarização; d) em 2002 o RACCI instala um radar meteorológico Doppler Banda S em Rondônia para ver o impacto das queimadas na formação e desenvolvimento da chuva; e) $\mathrm{O}$ projeto temático CHUVA utiliza um radar meteorológico Doppler Banda $\mathrm{X}$ de Dupla Polarização móvel para caracterizar a chuva no Brasil a partir de diversos experimentos ao longo de 2011 a 2014.

Apesar de toda infraestrutura existente no Brasil, ainda não dispomos de um centro de pesquisa ou um centro operacional de meteorologia por radar que viabilize a integração dos diversos radares meteorológicos, uma vez que os radares pertencem a diversas instituições. A integração por sua vez não é simplesmente um mosaico de campos de chuva ou fator refletividade do radar (Z), mas envolve diversos aspectos técnicos.

Os radares meteorológicos se baseiam no princípio da emissão de pulsos de radiação eletromagnética confinada em um ângulo sólido definido por uma antena parabólica (Equação 1). A potência transmitida (Pt) por sua vez, interage com os hidrometeoros que retro espalham uma parte da energia de volta $(\sigma)$ para a antena do radar. Sendo que a energia recebida $(\mathrm{Pr})$ pelo radar é pelo menos 7 ordens de magnitude menor do que a transmitida e diminui com o inverso da distância (r) ao quadrado. Portanto, à medida que o feixe do radar se distância, potência recebida tem que maior o que a potência mínima detectável, Figura 1.

$$
\bar{P}_{R}=\frac{P_{T} G^{2} \theta \varphi h \lambda^{2}}{16 \bullet 64 \bullet \pi^{2}(\ln 2)} \frac{1}{r^{2}} \sum_{\text {volume }} \sigma_{i}
$$

Os parâmetros $G, \theta, \varphi$, h representam o ganho da antena, largura horizontal e vertical da antena, altura do feixe da antena na distância $r$ do radar e descrevem o volume iluminado pelo radar respectivamente enquanto que $\lambda$ é comprimento de onda incidente. Sendo que a seção transversal de retro espalhamento $(\sigma)$ em um regime de espalhamento Rayleigh é definida como o fator refletividade do radar efetivo (Ze), logo a equação (1) pode ser manipulada para avaliarmos como Ze varia em função da distância do alvo e da potência transmitida e recebida, equação (2).

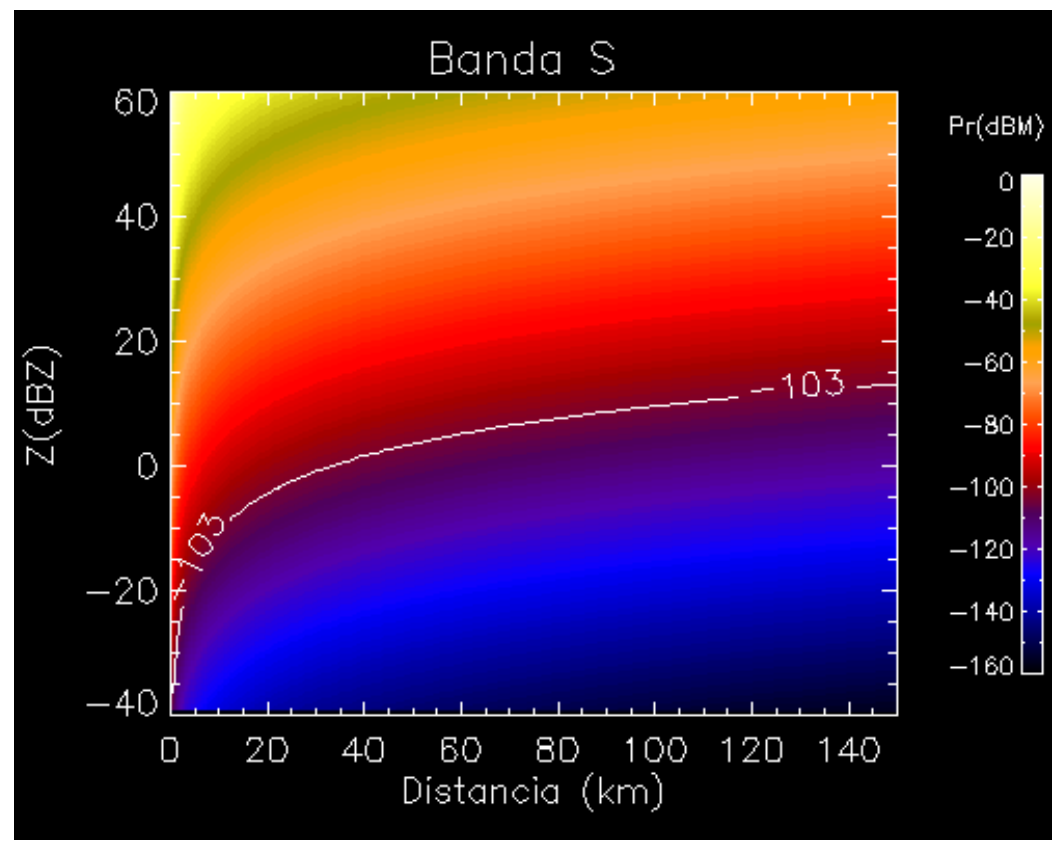

Figura 1 - Variação da Potência Recebida em função da distância e do Fator Refletividade do Radar. 
A curva de 103 dB expressa a Potência Mínima Detectável (MDS) por um radar meteorológico

$$
Z_{e}=\frac{\bar{P}_{R}}{P_{T}} \bullet \frac{r^{2}}{|K|^{2} C t e}
$$

(Equação 2)

Neste sentido, podemos utilizar as equações 1 e 2 e ressaltar que Ze depende da potência transmita que por sua vez é dependente de uma válvula (Magnetron ou Klytron) que tem um tempo de vida útil e decai continuamente com o tempo. Dessa forma, é imprescindível monitorar temporalmente a variação da $\mathrm{P}_{\mathrm{T}}$ para obter o valor correto de Ze. Entretanto, os softwares de controle do radar atualmente ainda não atualizam em tempo real os valores da $P_{\mathrm{T}}$ na equação do radar, somente armazenam nos LOG files BITE desde que o usuário ative esta opção. Além do mais, o ganho da antena também se altera com o tempo devido as intempéries causadas pela umidade, chuva e vento, bem como o molhamento da redoma (Gorguchi et al., 2013; Salazar-Cerreño et al., 2014). Finalmente vale a pena ressaltar que $\mathrm{Ze}$ tende a aumentar com a distância, uma vez que o volume iluminado pelo radar aumenta e a potência diminui.

Dessa maneira, a integração de uma rede de radares meteorológicos deve levar em conta as características intrínsecas dos equipamentos tais como a distância e a largura do feixe da antena e a respectiva calibração do radar que pode variar com o tempo (Anagnostou et al., 2000). As calibrações demandam tempo e pessoal especializado e algumas devem ser feitas diariamente, semanalmente ou mensalmente. Por exemplo, o Sol é utilizado para verificar o posicionamento da antena, ganho da antena e calibração do receptor que também pode ser feito por um gerador de sinal externo. As esferas metálicas ou tetraedros servem para verificar as perdas da transmissão e recepção do sinal, bem como a Pт (Scarchilli et al., 1995;
Gekat et al., 2010).

Uma vez que o Brasil dispõe de diversos radares meteorológicos e estas informações começam a ser disponibilizadas publicamente e para alguns órgãos brasileiros, faz-se necessário implementar metodologias de integração dos dados de radar que sejam adequadas e viabilizem a construção de mapas de chuva não somente qualitativos mas também mapas quantitativos de chuva na superfície.

Dessa maneira, este estudo apresenta uma metodologia para fazer a integração de uma rede de radares meteorológicos abordando desde aspectos de calibração (seção 3), a características intrínsecas do radar e métodos de interpolação (seção 4). Para tanto, este estudo utilizará os 3 radares meteorológicos do estado de São Paulo como exemplo e o radar de precipitação do Tropical Rainfall Measuring Mission (TRMM) (Kummerow et al., 1998) para calibrar e avaliar a integração.

\section{DADOS DE RADAR}

Neste estudo de integração são utilizados os dados volumétricos dos radares meteorológicos de Presidente Prudente e Bauru do IPMet/UNESP e o de Salesópolis do DAEE/FCTH durante o período de Dezembro de 2002 a Março de 2003.

Além destes radares, os dados volumétricos do radar de precipitação (PR) a bordo do satélite TRMM (Kummerow, et al., 1998) são utilizados como observação de referência para a calibração dos radares de superfície. Uma vez que o TRMM-PR opera em uma banda de frequência atenuante, este estudo utiliza os dados volumétricos do algoritmo 2A25 que corrige $\mathrm{o}$ fator refletividade do radar pela atenuação da chuva (Iguchi at al.,2000) além de disponibilizar a classificação do tipo de chuva (convectivo, estratiforme e outros) (Awaka et al., 1997) que é inerente no algoritmo 2A23. As características técnicas de cada um dos radares utilizados neste estudo estão descritas na Tabela 1. 
Tabela 1- Especificações dos Radares Meteorológicos

\begin{tabular}{|l|r|r|r|r|}
\hline & Presidente Prudente & \multicolumn{1}{c|}{ Bauru } & \multicolumn{1}{c|}{ CTH } & \multicolumn{1}{c|}{ TRMM } \\
\hline Fabricante & $\begin{array}{c}\text { EEC } \\
\text { Enterprise }\end{array}$ & $\begin{array}{c}\text { EEC } \\
\text { Enterprise }\end{array}$ & $\begin{array}{c}\text { McGill } \\
\text { University }\end{array}$ & NASDA/CRL \\
\hline $\begin{array}{l}\text { Comprimento de onda } \\
(\mathrm{cm})\end{array}$ & 10,68 & 10,68 & 10,0 & 2,17 \\
\hline Largura do Feixe & $22^{\circ}$ & $2^{\circ}$ & $2,1^{\circ}$ & $0,71^{\circ}$ \\
\hline PRF & 621 & 620 & 250 & 2776 \\
\hline Número Elevações & 10 & 11 & 20 & - \\
\hline Varreduras Azimutais & 360 & 360 & 360 & 49 \\
\hline Tamanho do gate $(\mathrm{km})$ & 1 & 1 & $0,5($ até $60 \mathrm{~km})$ & 0,25 \\
& 240 & & $2,0(60-120 \mathrm{~km})$ & \\
\hline Número de bins & $-51,383606$ & $-49,026917$ & $-45,972222$ & 80 \\
\hline Longitude & $-22,117767$ & $-22,357788$ & $-23,600000$ & \\
\hline Latitude & 460 & 624 & 925 & $350 \mathrm{~km}$ \\
\hline Altura $(\mathrm{m})$ & & &
\end{tabular}

\section{CALIBRAÇÃO DOS RADARES}

Uma vez que não é possível avaliar se os radares meteorológicos passaram por calibrações rotineiras ou mesmo saber sobre o tempo de vida útil das válvulas ou a série temporal da potência transmitida, este estudo utiliza a metodologia desenvolvida por Anagnostou et al. (2001) para calibrar os radares de forma independente.

De uma forma resumida, Anagnostou et al. (2001) desenvolveram uma metodologia capaz de calibrar os radares meteorológicos da rede americana NEXRAD e os utilizados nas campanhas experimentais do TRMM ao longo de 1998 a 2000 a partir de medidas independentes do radar de precipitação(PR) do TRMM. Diferentemente dos procedimentos padrões que utilizam geradores de sinal e esferas metálicas, neste procedimento de calibração o TRMM-PR é utilizado como referência, pois dispõe de uma estabilidade confiável, é calibrado a cada vez que sobrevoa o radar calibrador ativo (ARC) localizado no Japão e sempre observa a superfície e possui uma sensibilidade de 0.8 dB (Kawanishi et al., 2000). No Brasil este procedimento foi aplicado aos radares do IPMet/USP (Anagnostou et al., 2000) e do DECEA (Costa, 2007).

Uma vez que os radares meteorológicos da FCTH e IPMet são banda S e o do TRMM é banda $\mathrm{Ku}$, temos que definir uma região de tamanho de partículas onde ambas a medidas de Ze sejam comparáveis e estejam dentro do regime de espalhamento Rayleigh. Adicionalmente, temos que lembrar que PR sofre mais atenuação que um radar banda $S$, portanto limitamos às comparações entre as alturas de 7 e $15 \mathrm{~km}$, que apresentam classificação de chuva estratiforme e tem valores de Ze menor que $35 \mathrm{dBZ}$ (Anagnostou et al., 2001). Dessa forma, é possível garantir que somente cristais de gelo pequeno estejam presentes dentro do volume iluminado tanto pelo TRMM-PR como os radares de superfície, e assim garantir uma diferença máxima de 1,5 dBZ (valor esperado entre uma Banda S e K para o mesmo conteúdo de água liquida)

Por exemplo, na Figura 2 são apresentados mapas de Ze (Indicadores de Posição de Plano a Nível constante de Altura - CAPPI) a $2 \mathrm{~km}$ de altura para medidas coincidentes entre os radares de superfície (esquerda) e pelo satélite TRMM-PR (à direita).

Na Figura 2a e 2b é possível observar no alto das duas figuras uma célula de tempestade, na qual de acordo com o radar de Salesópolis, o núcleo em vermelho, possui em torno de $50 \mathrm{dBZ}$, 
(a) Salesópolis - FCTH

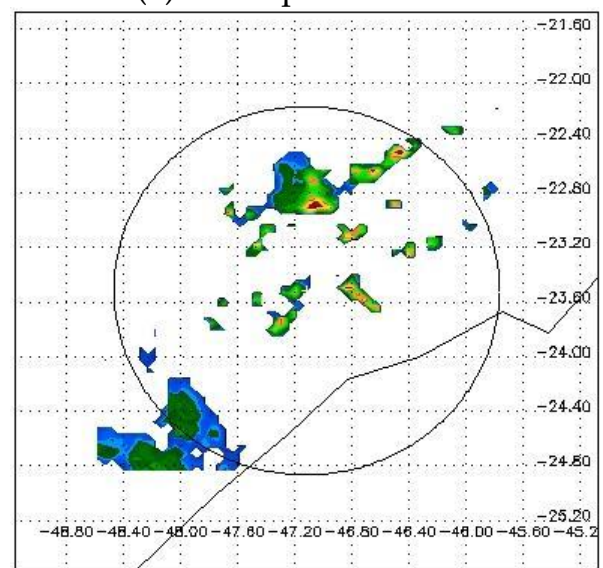

(c) Presidente Prudente - IPMet

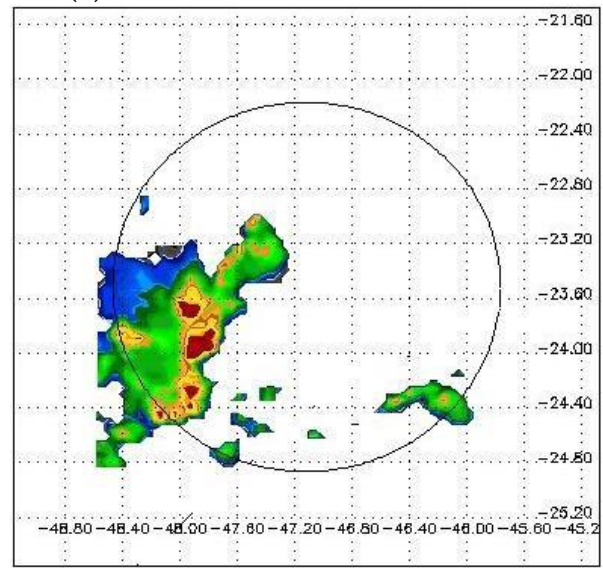

(e) Bauru - IPMet

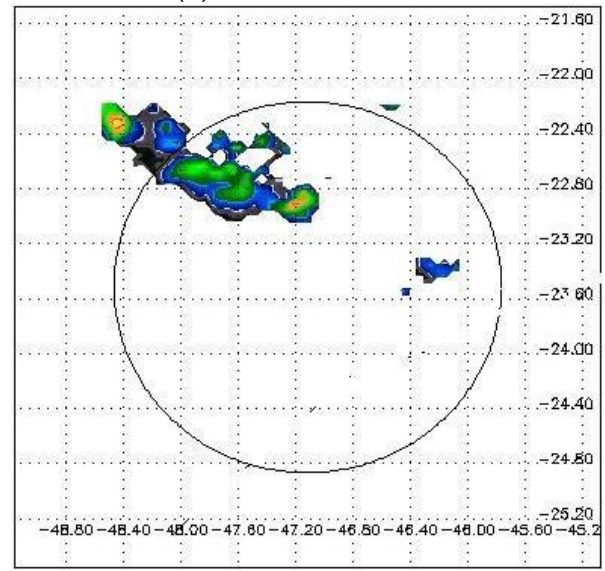

(b) Salesópolis - TRMM-PR

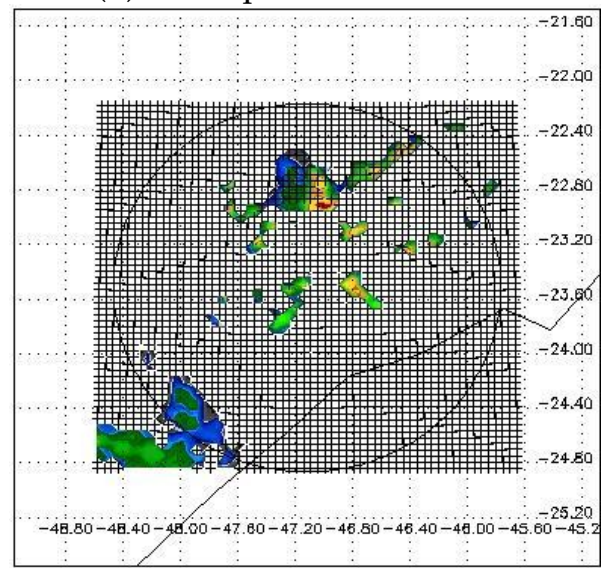

(d) Presidente Prudente - TRMM-PR

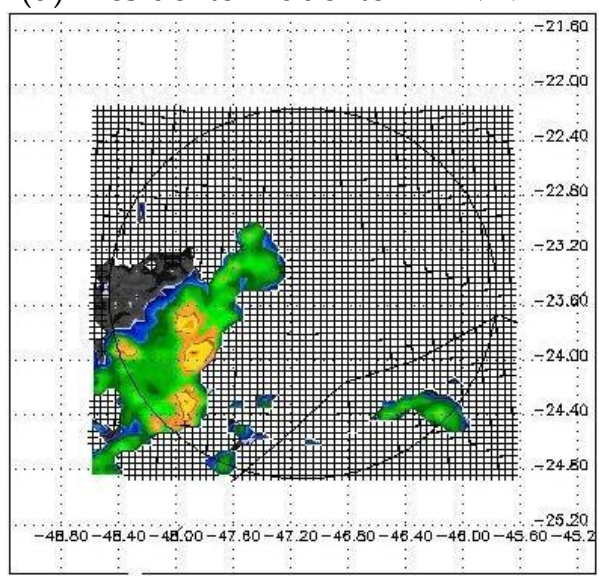

(f) Bauru - TRMM-PR

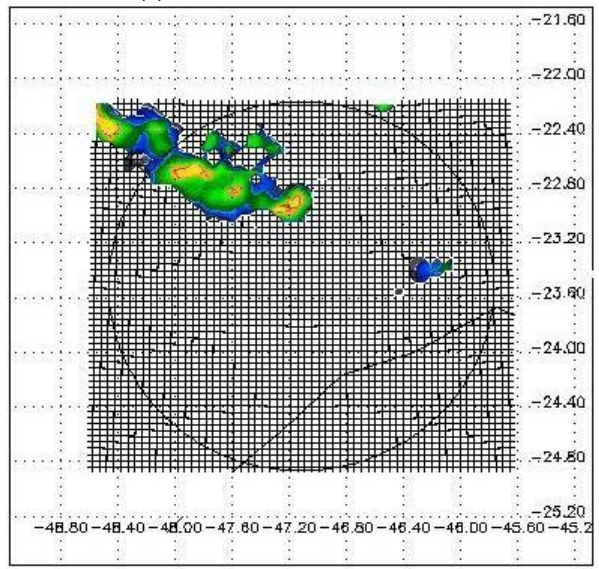

Figura 2 - (a) e (b) Medidas do radar de Salesópolis da FCTH e TRMM-PR em 09/03/2003 às 14:16 GMT. (c) e (d) Medidas do radar de Presidentes Prudente do IPMet e TRMM-PR em 01/01/2003, às 17:16 GMT. (e) e (f) Medidas do radar de Bauru do IPMet e TRMM-PR em 20/12/2002, às 07:08 
enquanto que o TRMM observa o mesmo núcleo com valores entre 45 e 55 dBZ. Já nas células um pouco abaixo, menores e menos intensas, a refletividade obtida pelo sensor do TRMM é mais alta, indicando a possibilidade do radar da FCTH de subestimar os limiares inferiores da refletividade. Na Figura 2c e 2d pode-se observar que nos núcleos mais intensos de da célula convectiva, o radar de Presidente Prudente superestima Ze, e com menor intensidade na célula no quadrante sul. Finalmente na Figura 2e e 2f, pode-se notar que nos núcleos mais intensos de refletividade do radar (acima de $40 \mathrm{dBZ}$ ) o radar de Bauru apresenta menores valores de Ze.

Para saber exatamente a diferença entre as observações, podemos comparar pixel a pixel ou a partir das distribuições de probabilidade nas regiões coincidentes. Entretanto, como os radares dispõem de geometria e características distintas, as medidas não são completamente coincidentes, portanto precisamos definir uma base comum de comparação dentro de um espaço tri- dimensional definido por um cubo 3D.

Baseado nas características dos radares meteorológicos, Tabela 1 , o cubo 3D será baseado na construção de indicadores de plano de posição a altitude constante (CAPPI) com resolução de $5 \times 5 \mathrm{~km}$ na horizontal e 2 $\mathrm{km}$ de resolução vertical de acordo com o procedimento desenvolvido por Anagnostou e Krajewski (1997), tanto para os radares da FCTH e IPMet como para o TRMM-PR, desde $2 \mathrm{~km}$ até $10 \mathrm{~km}$ de altura Além disso, as comparações se limitam até uma distância de $60 \mathrm{~km}$ do radar tanto para os radares do DAEE/FCTH como os do IPMet pois a antena tem largura de feixe maior que 2,0\%, pois após esta distância o volume iluminado tem uma espessura maior que de $2 \mathrm{~km}$ de altura. Finalmente a comparação é feita a partir das medidas coincidentes entre 7 e $10 \mathrm{~km}$ para pixels classificados como estratiforme e com Ze do TRMM-PR entre 18 e 35 dBZ de forma a garantir a presença de pequenas partículas de gelo.

(a) Salesópolis - FCTH
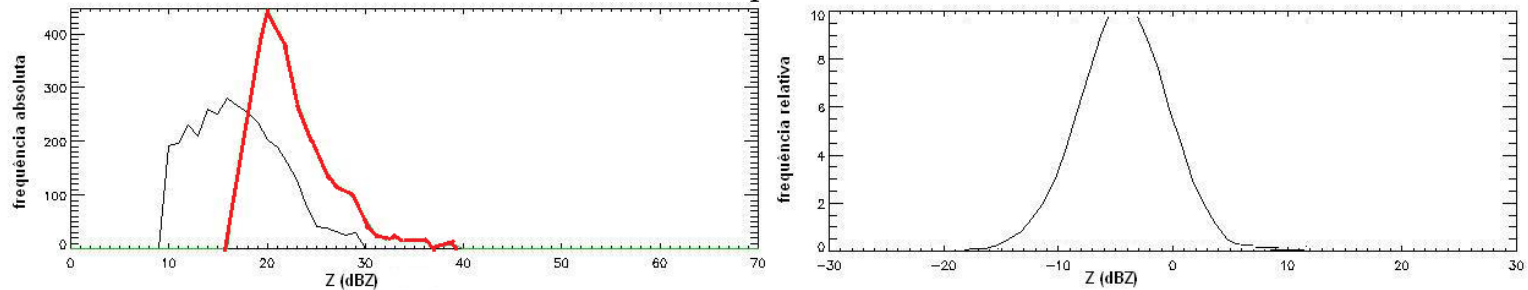

(b) Presidente Prudente - IPMet
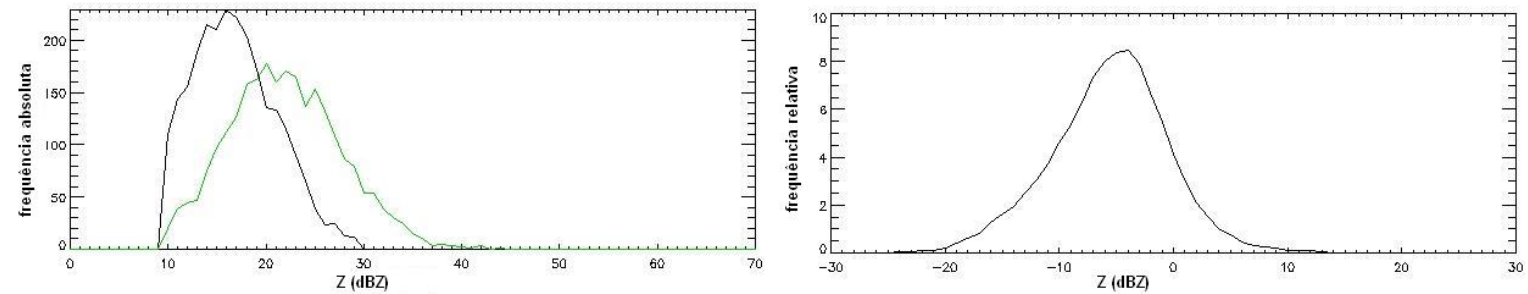

(c) Bauru - IPMet
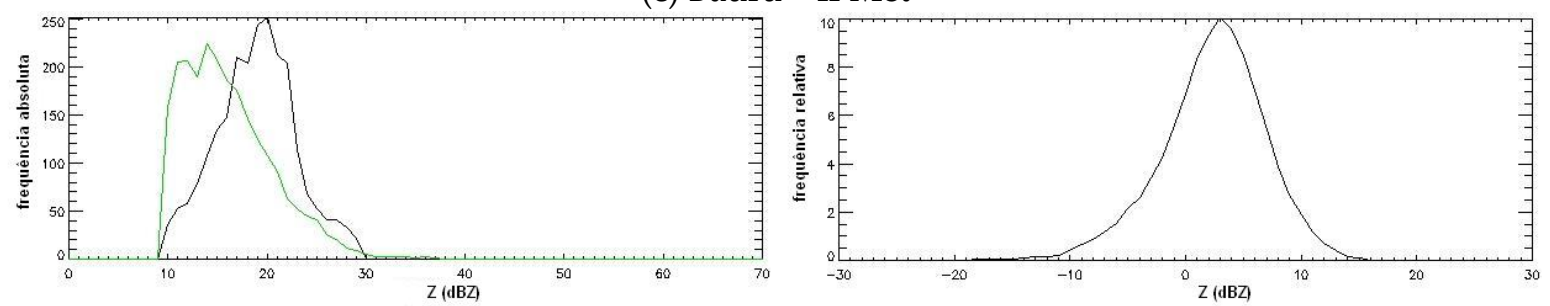

Figure 3 - Distribuição de probabilidade de ocorrência de refletividade do radar observada pelos radares de superfície e TRMM-PR (esquerda) e diferença entre Ze do radar de superfície TMM-PR

(direita) para os casos da Figura 2. (a) Salesópolis, (b) Presidente Prudente, (c) Bauru 
Seguindo os procedimentos descritos acima, podemos comparar as medidas entre os diferentes radares. Por exemplo, nos painéis da Figura 3 são apresentadas as distribuições de probabilidade de frequência de ocorrência do fator refletividade do para medidas coincidentes entre os radares de superfície e o TRMM-PR durante os eventos da Figura 2 e as respectivas diferenças de Ze.

$\mathrm{Na}$ figura 3a pode-se observar que as medidas do TRMM-PR (vermelho) apresentam maiores valores de Ze o que implica em uma subestimativa nas medidas do radar da FCTH. Para o evento de Presidente Prudente, Figura 3b, apesar das Figuras $2 \mathrm{c}$ e $2 \mathrm{~d}$ indicarem que havia uma superestimava, a distribuição de probabilidade entre 7 e $10 \mathrm{~km}$ implica o oposto, ou seja, um bias médio próximo de 4,5 dBZ. Finalmente para o radar de Bauru, Figura 3c, temos que apesar da Figura 2e e $2 \mathrm{f}$ indicarem que o radar do IPMet subestimava a precipitação em $2 \mathrm{~km}$, ao analisarmos a distribuição de probabilidade acima, observase o contrário, ou seja, uma superestimativa de $\sim 5 \mathrm{dBZ}$.

De maneira, para calcular o viés de cada radar, deve-se analisar a variação temporal das medidas e observar se existe um efeito persistente que decai com o tempo (queda de potência da válvula) ou é um efeito pontual. Portanto, para calcular o bias, podese utilizar a distribuição de probabilidade das diferenças entre as medidas coincidentes dos dois radares, ou a diferença entre as probabilidades cumulativas de ocorrência das duas distribuições de Ze obtidas a partir da minimização de uma função de custo (Anagnostou et al., 2001). Nos exemplos da Figure 3 temos a distribuição de frequência da diferença das medidas coincidentes de Ze, ou seja, ZGround-ZPr, que indicou um bias de $-4,5$
dBZ para os radares de Salesópolis e Presidente Prudente e $5 \mathrm{dBZ}$ para Bauru. Logo, este offset deve ser somado às medidas de refletividade do radar, conforme a equação 3 (conversão da equação 2 de $\mathrm{mm} 6 / \mathrm{m} 3$ para $\mathrm{dBZ})$

$$
\begin{aligned}
& Z_{e}[d B Z]=10 \log \bar{P}_{R}-10 \log P_{T}+ \\
& 20 \log r-10 \log |K|^{2}-10 \log C t e+\text { Bias }
\end{aligned}
$$

(Equação 3)

\section{a) Salesópolis- FCTH}

Para o radar de Salesópolis foi possível encontrar 22 eventos coincidentes entre o TRMM-PR e o radar da DAEE/FCTH durante $1 / 12 / 2002$ a 31/3/2003, sendo que o bias de cada evento é apresentado na Figura $4 \mathrm{a}$, bem como a diferença entre as medidas coincidentes em função de Ze do TRMM-PR.

Se consideremos o valor médio do bias como a média entre todos os 22 eventos teríamos um valor médio de $-4,13735 \mathrm{dBZ}$ (linha preta) com um desvio padrão de $\pm 3,5$ dBZ. No caso do radar meteorológico de Salesópolis, praticamente quase todos os eventos estiveram dentro dos limites do desvio padrão e apresentaram um subestimativa. Ao analisarmos como o viés varia em função de Ze (Figura $4 \mathrm{~b}$ ) pode-se observar que o radar do DAEE/FCTH subestima basicamente abaixo de $25 \mathrm{dBZ}$ e para valores maiores observa-se uma maior dispersão o que pode indicar algum efeito de distância. De todos os modos, calculando o viés segundo a metodologia de Anagnostou et al. (2001) o radar da FCTH tem um bias de $6.01469 \mathrm{dBZ}$. 
(a)

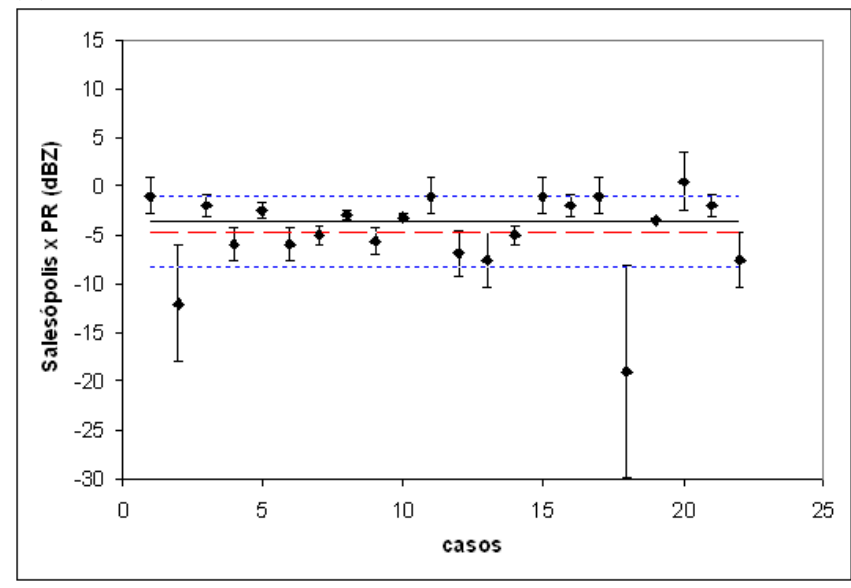

(b)

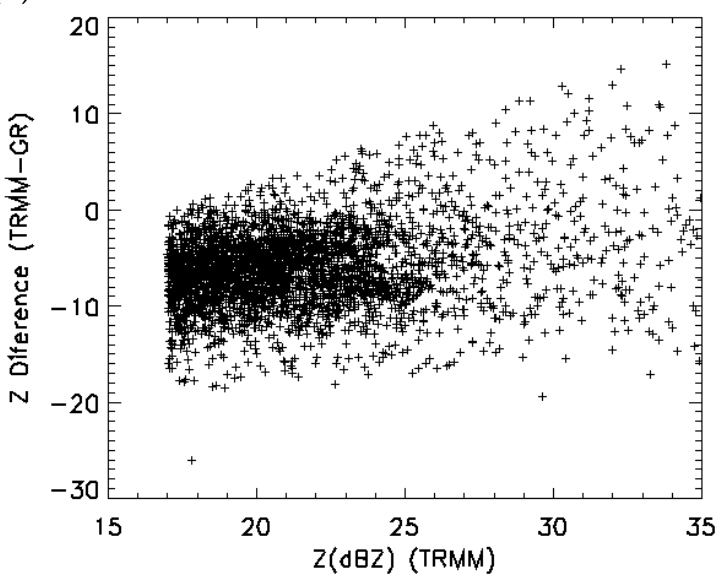

Figura 4 - (a) Série temporal da diferença média entre o radar da FCTH e TRMM-PR. A linha preta representa o valor do viés médio sobre os vieses de cada evento. As linhas pontilhas em azul representam o desvio padrão da distribuição média, enquanto que a linha tracejada vermelha o viés médio considerando-se uma distribuição de probabilidade. (b) diferença entre pixels coincidentes do TRMM-PR e FCTH em função de Ze do TRMM-PR

\section{b) Presidente Prudente}

Para o radar de Presidente Prudente, 24 eventos coincidentes foram observados durante Dezembro de 2002 a Março de 2003. A variação do bias médio de cada evento e o respectivo desvio padrão estão ilustrados na Figura 5a e a dispersão da diferença na Figura $5 b$.

A partir do bias médio das 24 medidas coincidentes obtém-se um valor médio de $-5,53340 \mathrm{dBZ}$ (linha sólida preta) com um desvio padrão de $\pm 5 \mathrm{dBZ}$ (linha azul tracejada). Porém utilizando a distribuição das diferenças, conforme Anagnostou et al. (2001) o bias médio é $-4,45671 \mathrm{dBZ}$.

Ao contrário do radar de Salesópolis, mesmo com o intervalo maior (desvio padrão), $25 \%$ dos casos ficaram para fora desses limiares, o que pode indicar uma flutuação na calibração do equipamento ou mesmo na potência transmitida. Porém observa-se que na maioria dos casos, o radar de Presidente Prudente subestimava a precipitação. De todas as maneiras é possível observar que existe um viés negativo conforme a Figura $5 b$ (a)

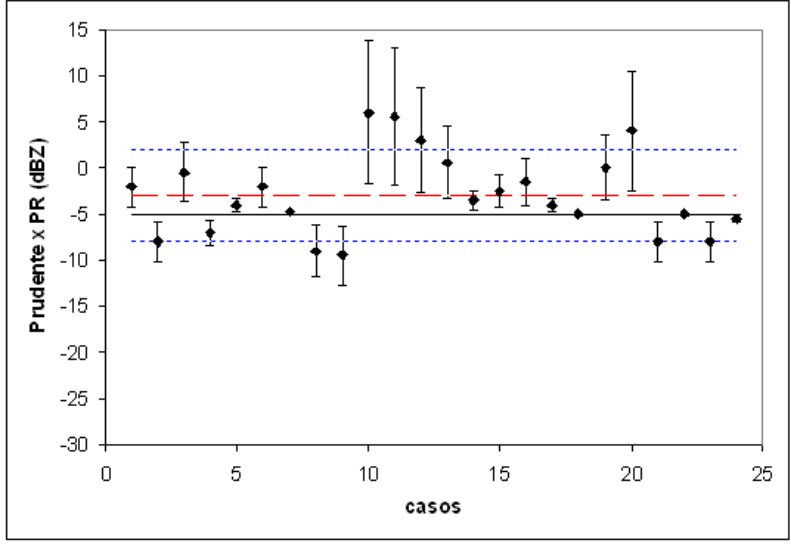

(b)

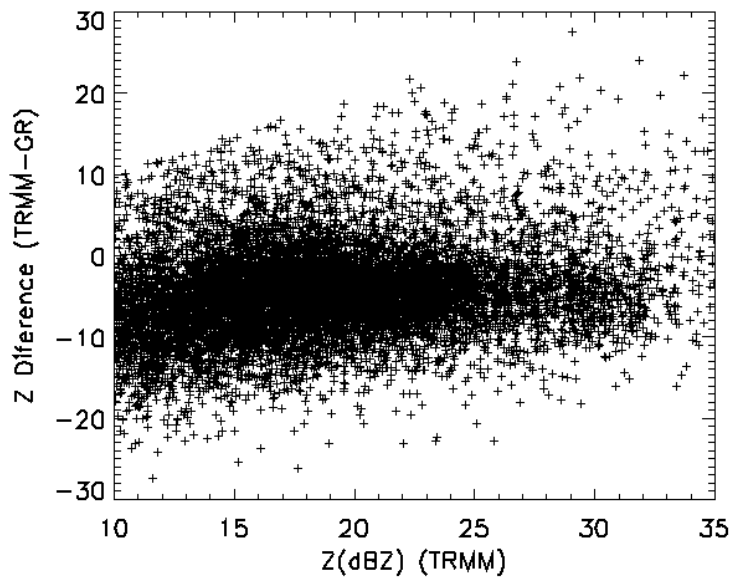

Figura 5 - Idem a Figura 4 porém para o radar meteorológico de Presidente Prudente 
c) Bauru

Para o radar de Bauru foi possível encontrar 26 eventos coincidentes com o TRMM durante o período de Dezembro de 2002 a Março de 2003. O primeiro resultado que chama a atenção em relação aos radares anteriores, Figura 6a, é a grande quantidade de pontos fora dos limites do desvio padrão da amostra, ou seja, mais de $50 \%$ dos eventos analisados. Este efeito reforça a necessidade de avaliar o desempenho do processo de integração dos radares nas áreas de sobreposição pois pode comprometer o resultado final.

Baseado no bias médio de cada

(a)

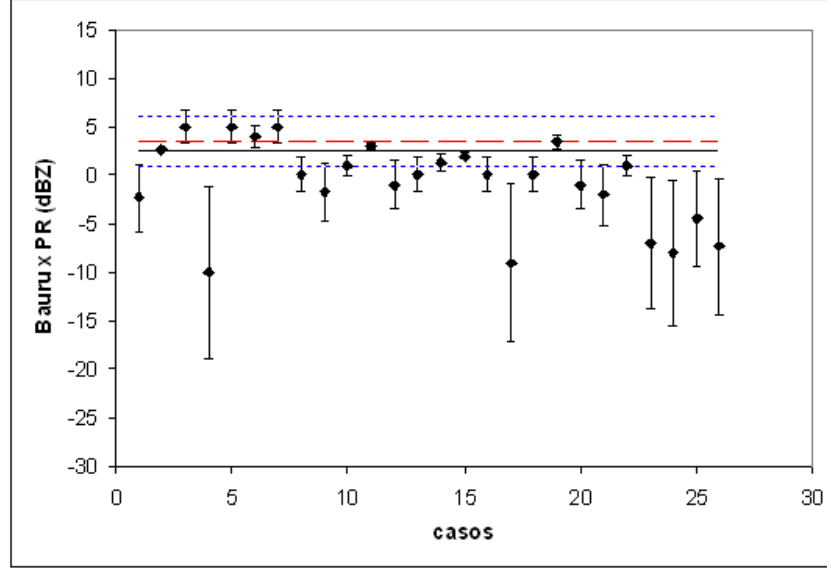

evento, o viés médio seria de $+2,52645 \mathrm{dBZ}$ (linha preta sólida) com um desvio padrão de $\pm 2,5 \mathrm{dBZ}$. Como se observa uma variabilidade aleatória no bias médio de cada evento é factível de afirmar que deve existir outra fonte de erro. Ao analisar o digrama de dispersão, Figura 6b, pode-se observar que existe uma tendência de superestimativa e que para valores maiores do que $20 \mathrm{dBZ}$ ocorre um aumento desta dispersão. Aplicando a metodologia de Anagnostou et al. (2001) em toda a população temos um bias de +4.28497 $\mathrm{dBZ}$

(b)

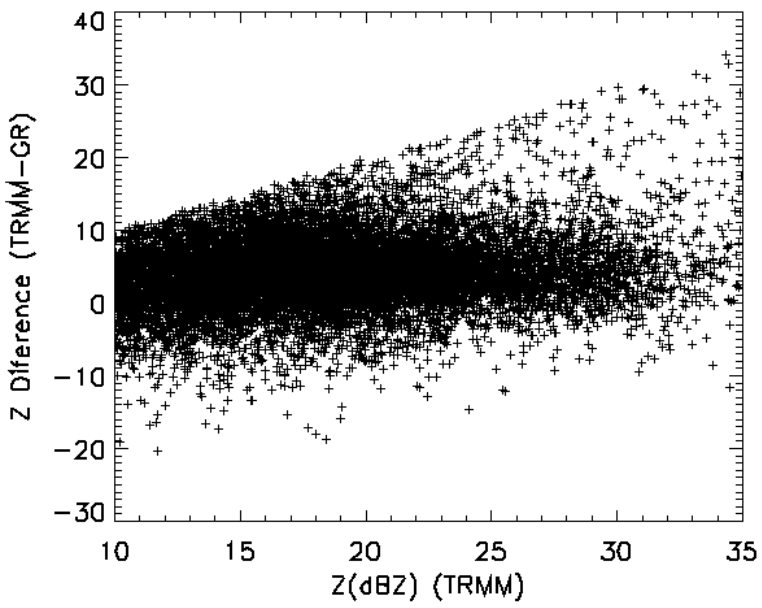

Figura 6 - Idem a Figura 4 porém para o radar meteorológico de Bauru

\section{d) Aplicação da Calibração}

Após o cálculo individual do bias de cada radar, os bias (tabela 2) foram somados às medidas de $\mathrm{Ze}$ e os CAPPIs foram novamente refeitos. $\mathrm{Na}$ Figura 7 é apresentado a Ze observada pelos de superfície e os valores correspondentes do TRMM-PR dentro do cubo 3D antes e depois da calibração. Como esperado, após a aplicação da correção as medidas de Ze são mais consistentes com as observações do TRMM.

Tabela 2 - Bias calculado para cada radar meteorológico

\begin{tabular}{|l|l|l|l|}
\hline Radar & Salesópolis & Presidente Prudente & Bauru \\
\hline Bias (dBZ) & $-6,01469$ & $-4,45671$ & $+4,28497$ \\
\hline
\end{tabular}


Sem correção
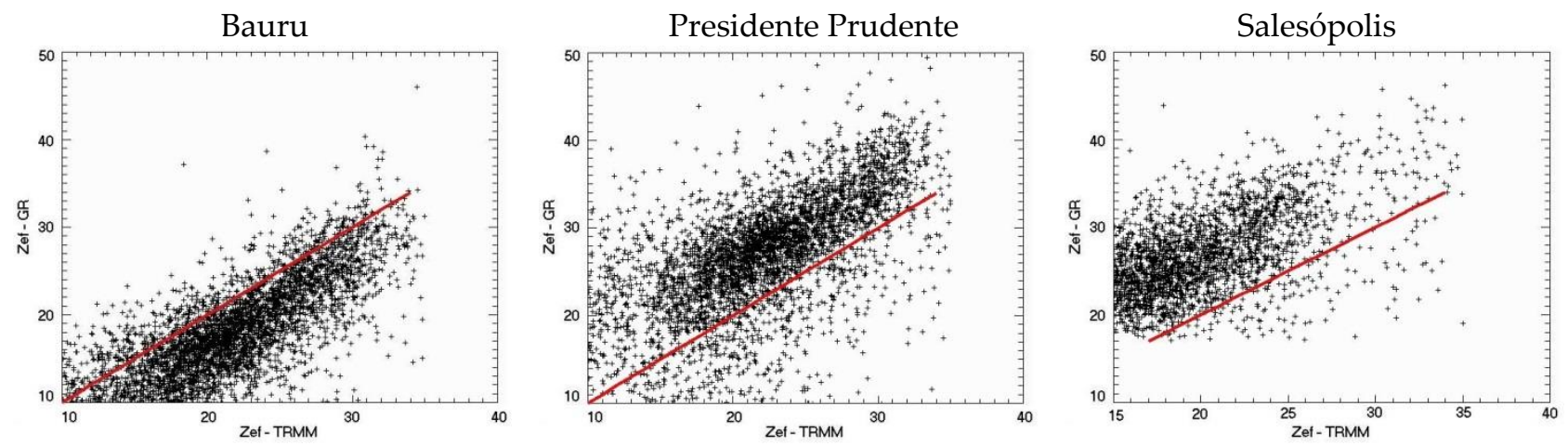

Após correção
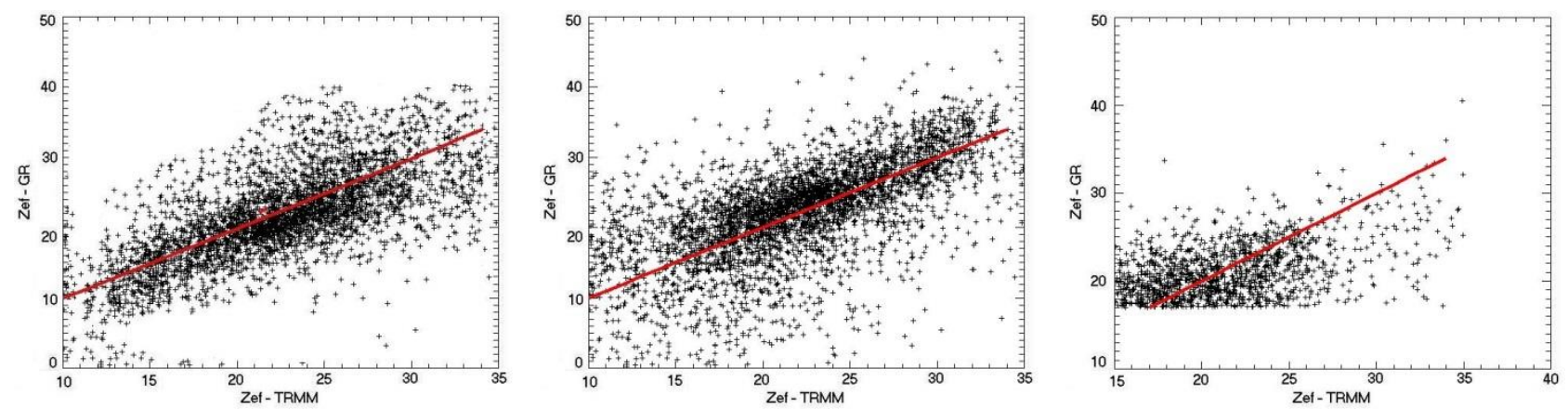

Figura 7 - Da esquerda para a direita: radares meteorológicos de Bauru, Presidente Prudente e Salesópolis. Painel superior: diagramas de espalhamento entre Z do TRMM-PR e respectivos radares sem correção; Painel inferior com correção do bias. A linha vermelha indica os valores iguais de Ze entre ambos os radares

\section{INTEGRAÇÃO DOS RADARES METEOROLÓGICOS}

O processo de integração consiste na elaboração de um mapa 3D da precipitação observada pelos diversos radares meteorológicos. As informações processadas para cada ponto no espaço 3D devem considerar as características intrínsecas de cada radar, ou seja, distância entre o volume iluminado e ponto no espaço e a respectiva fração do volume iluminado, largura do feixe da antena e potência por exemplo.

Neste estudo são apresentados dois procedimentos de integração: Integração de CAPPI e Integração Volumétrica. A integração abrangerá todo o estado de São Paulo e portanto será usado a varredura completa de $240 \mathrm{~km}$ de cada radar. Como os radares possuem resoluções diferentes, Tabela 1 (largura do feixe $2^{\circ}$ e resolução de gate variando de 0,5 a $2,0 \mathrm{~km}$ ), a resolução da integração será de $5 \times 5 \mathrm{~km}$ na horizontal e 2 $\mathrm{km}$ na vertical. Independente do procedimento abaixo, os CAPPI serão calculados segundo a metodologia proposta por Anagnostou e Krajewski (1997) com as resoluções definidas anteriormente. Dessa forma, espera-se capturar a estrutura 3D da precipitação sem "buracos" de observação.

\section{a) Integração de CAPPI}

Neste procedimento, as matrizes dos CAPPI de $3 \mathrm{~km}$ de altura de cada um dos 3 radares possuem resolução igual à matriz do Estado de São Paulo (3D-PPT), ou seja, $5 \mathrm{~km} x$ $5 \mathrm{~km}$. Como ambos operam com alcance de $240 \mathrm{~km}$, temos então 3 matrizes de $96 \times 96$ pixels.

O valor da refletividade resultante é dado pela ponderação do fator refletividade do radar de cada pixel de um ou mais radares contidos em cada pixel da matriz 3D-PPT. O peso adotado é proporcional ao inverso da distância entre eles (Equação 3). Essa distância determina a fração com que cada pixel do 
radar contribui para o pixel da matriz do Estado de São Paulo.

A figura 8 apresenta a grade 3D-PPT (grade preta) com a sobreposição da grade CAPPI de um radar meteorológico (esquerda) e dois radares (direita) respectivamente. Neste exemplo, a matriz 3D-PPT que tem somente um radar, sendo que o pixel (cinza) da matriz 3D-PPT contém a contribuição de 4 pixels de um mesmo radar (grade azul com o centro

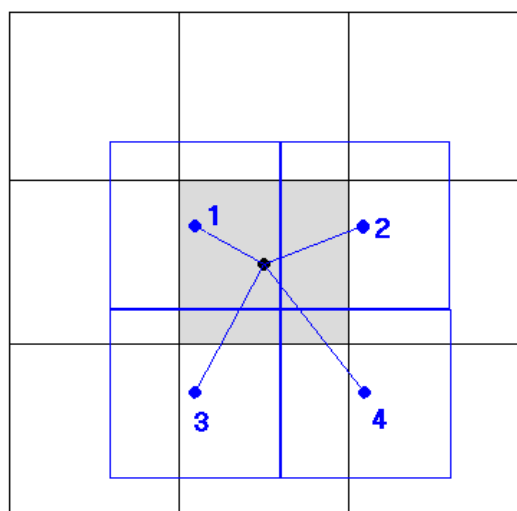

dos pixels indicados por 1, 2, 3 e 4). Quando temos dois radares, o processo é o mesmo para um pixel (cinza) que cobre uma área de interseção entre dois ou mais radares, Figura 8 (direita). Neste caso temos um radar que está representado pela grade azul identificada pelos pixels em 11, 12, 13 e 14 e o outro radar com a grade vermelha e pixels em 21, 22, 23 e 24.

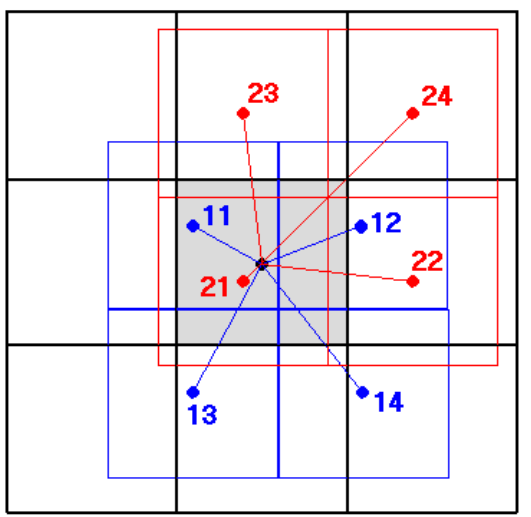

Figura 8 - Esquema de obtenção do CAPPI de um pixel da matriz 3D-PPT que contém pixels de um radar apenas e com dois radares respectivamente

Matematicamente, $\quad$ fator refletividade do radar $(Z)$ ponderado no pixel do CAPPI de integração é definido por:

$$
Z=\frac{\sum_{i=1}^{n} Z_{i} \omega_{i}}{\sum_{i=1}^{n} \omega_{i}}
$$

Equação (3)

onde $\mathrm{Zi}$ é o fator refletividade do radar de cada pixel do radar $\left(\mathrm{mm}^{6} / \mathrm{m}^{3}\right)$ e $\omega_{\mathrm{i}}$ é o peso atribuído a cada pixel de acordo com a fração contida no pixel da matriz 3D-PPT que é normalizado pela distância do pixel a seu respectivo radar $\left(\mathrm{d}_{\mathrm{i}}\right)$ e é dado por:

$$
\omega_{i}=\frac{1}{d_{i}}
$$

Equação (4)
É importante ressaltar que nos pontos onde ocorre a intersecção entre os radares, será possível comparar as medidas, logo uma outra maneira de determinar a calibração desses radares.

b) Integração Volumétrica

O segundo procedimento de integração, aqui denominada volumétrica, consiste em verificar para cada pixel da matriz 3D-PPT, a contribuição do volume iluminado (bin) de cada radar interceptando o cubo. A fração da contribuição é função do ângulo de elevação $(\varphi)$, da largura do feixe da antena $(\phi)$, da resolução do gate do bin e da distância $\left(\mathrm{r}_{\mathrm{i}}\right)$ que o radar se encontra do pixel da matriz 3DPPT. Logo, radares mais próximos terão maior contribuição. Para calcular este peso, o volume iluminado-VolBIN (eq. 5) é particionado em 10 elementos de volume e através do geo-referenciamento 3D deste bin verificamos quais estão contidos dentro do pixel 3D. Logo, normalizando pelo volume iluminado temos o peso de cada gate i dentro do cubo 3D (equação 7). 


$$
\operatorname{VolBIN}_{r i}=\frac{\pi \times \text { gate }}{3}\left[E_{2}^{2}+E_{1} E_{2}+E_{1}^{2}\right]
$$

onde E2 e E1 são as alturas da espessura do volume iluminado no gate i e i+1 que podem ser aproximadas por:

$$
E_{i}=r_{i} \sin \phi
$$

Equação (6)

Logo o peso de cada Bin pode ser expresso por:

$$
\omega_{i}=\frac{\sum_{j=1}^{10} \operatorname{VolBIN}_{r i_{j}} \times \delta}{\operatorname{VolBIN}_{r i}}
$$

Equação (7)

onde $\delta$ é 1 quando a décima parte do volume iluminado ri estiver dentro do pixel 3D e 0 quando não interceptar o volume. Finalmente, utiliza-se a equação (5) para calcular o fator refletividade do radar na área integrada, porém $\mathrm{Zi}$ é o Ze de cada Bin que contribui dentro do pixel 3D ponderado pela contribuição do seu volume dado pelo peso $\omega$ i.

Para exemplificar este procedimento, temos na figura 9 um exemplo de um pixel dentro da matriz 3D volumétrica que é interceptado por alguns bins de dois radares. Neste esquema temos que o pixel da matriz $3 \mathrm{D}$ volumétrica é interceptado por 5 bins do radar 1 ( 3 totalmente e 2 parcialmente) e por 4 bins do radar 2 (todos parcialmente). Isso efeito se deve ao fato de cada radar estar localizado em pontos diferentes em relação ao determinado pixel. Logo a contribuição de cada bin será proporcional a fração do volume amostrado dentro do pixel 3D em relação ao volume do Bin (equação 7).

Nesse exemplo, o radar 1 está mais próximo, o que podemos notar pelo feixe ser mais estreito e ter maior ângulo de elevação do radar. Enquanto o radar 2 tem feixe mais largo e menor ângulo de elevação do feixe. $\mathrm{O}$ ângulo azimutal de cada radar contribui na distribuição horizontal dos bins, dada pela transformação de coordenadas polares em cartesianas.

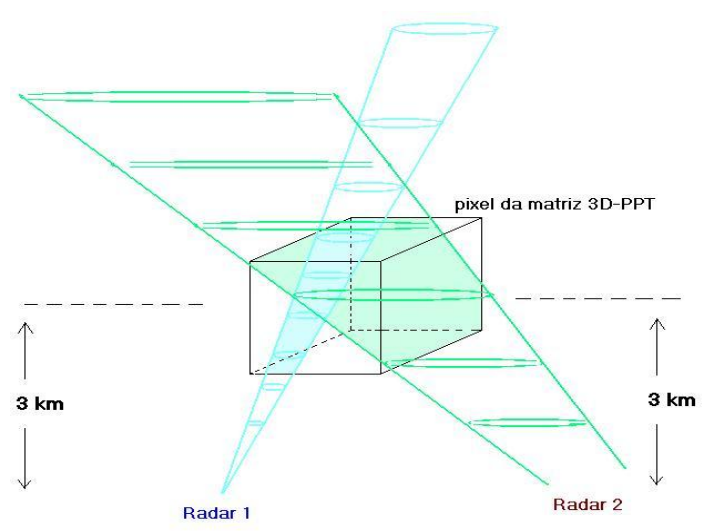

Figura 9. Pixel da matriz 3D-PPT interceptado por dois radares.

\section{RESULTADOS}

Para ilustrar os resultados da integração dos radares meteorológicos do estado de São Paulo, utilizamos primeiramente uma passagem do satélite TRMM em 4 de Fevereiro de 2013 as 00:31
GMT, Figura 10. As medidas coincidentes dos 3 radares meteorológicos de Presidente Prudente, Bauru e Salesópolis são apresentadas na Figura 11. Enquanto que a integração conforma o método de CAPPI e Volumétrico está disponível na Figura 12. 


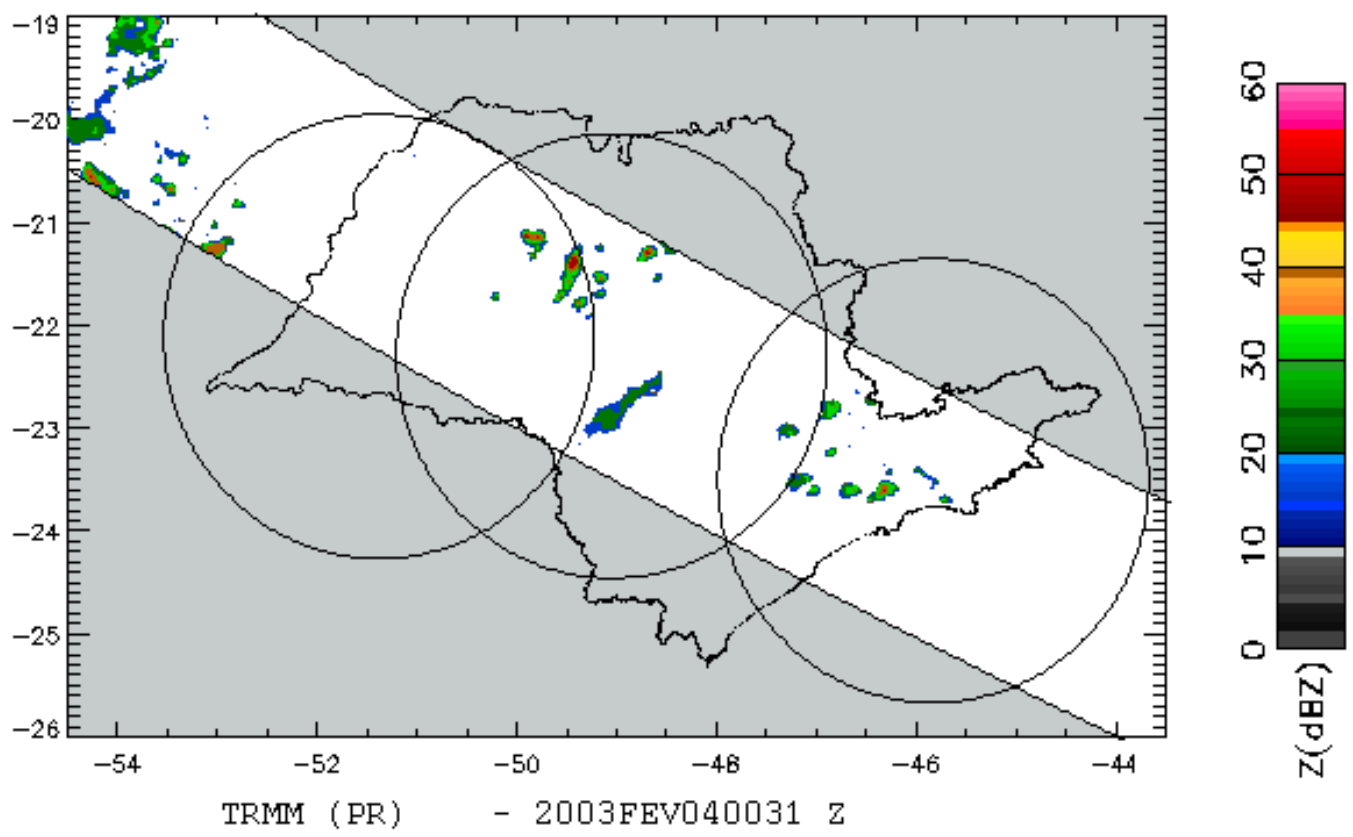

Figura 10 - CAPPI de 3km de altura observado pelo TRMM-PR em 4 de Fevereiro de 2003 as 00:31 GMT. A região delimitada em branco representa a área de cobertura do TRMM-PR que é de $250 \mathrm{~km}$

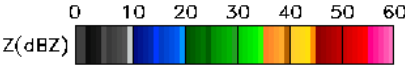

(a) Presidente Prudente

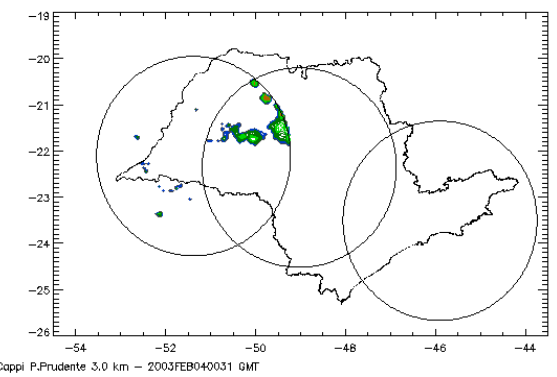

(b) Bauru

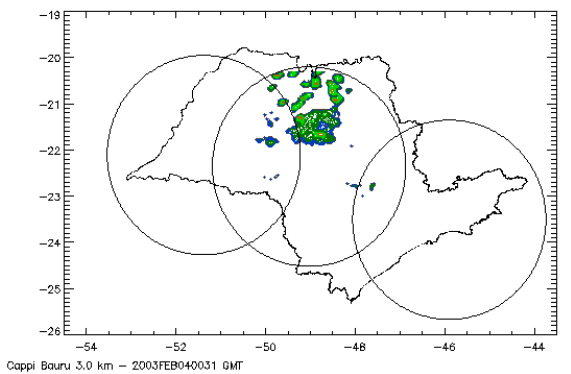

(c) Salesópolis

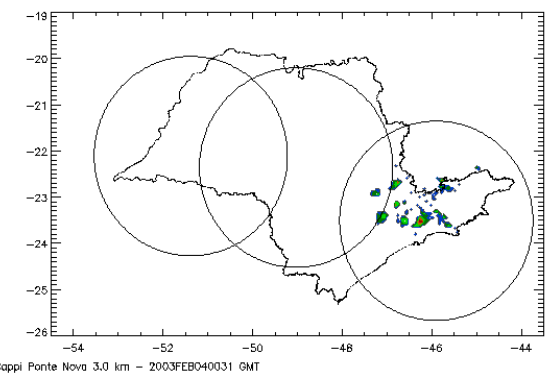

Figura 11 - Idem Figura 10, porém para os radares meteorológicos de (a) Presidente Prudentes; (b)

Bauru; e (c) Salesópolis. Os círculos representam uma área de cobertura de 240 km a partir do radar

$\mathrm{Z}(\mathrm{dBZ}) \stackrel{0}{0}$

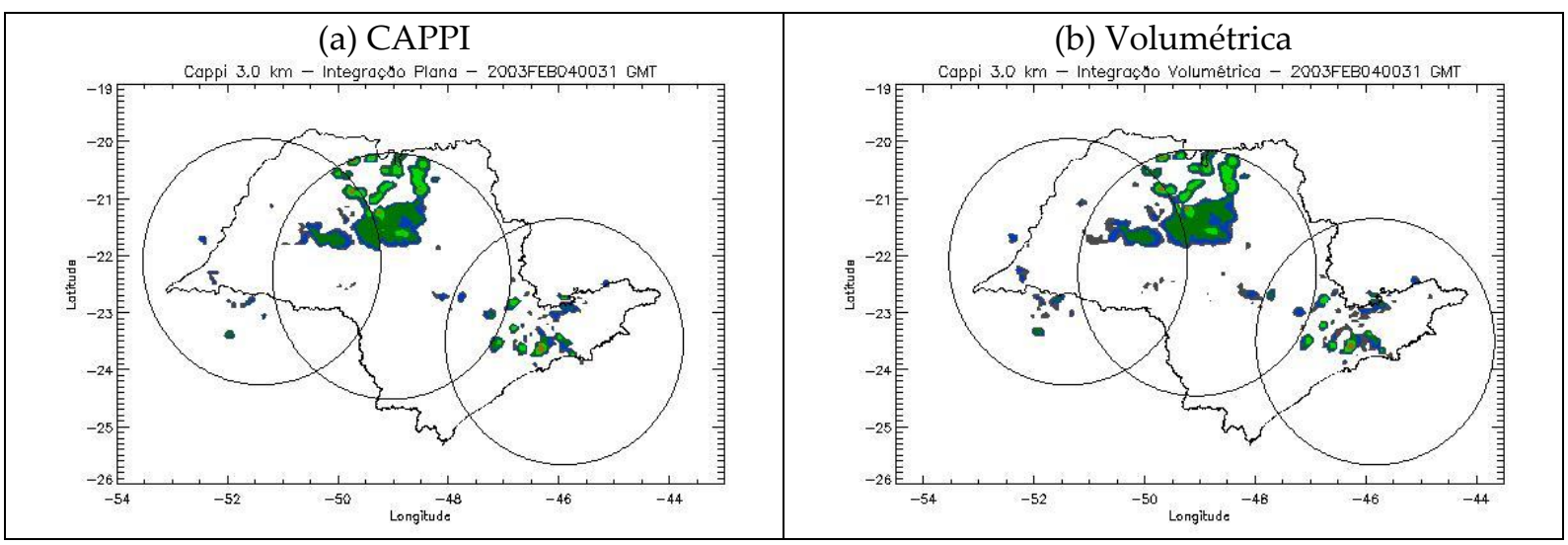

Figura 12. CAPPI de $3 \mathrm{~km}$ de altura resultante da integração dos radares de Presidente Prudente, Bauru e Ponte Nova, utilizando o método de integração dos CAPPI (a) e integração volumétrica (b). 
Pode-se observar que a integração volumétrica consegue capturar mais campos de precipitação, ou seja, a área é relativamente um pouco maior que a simples média feita na integração dos CAPPIs. De fato, a contribuição dos bins dentro do pixel 3D é evidente dentro das áreas de intersecção, pois os radares mais próximos terão um peso maior. Por exemplo, entre Presidente Prudente e Bauru, observa-se um peso maior para os campos observados por Presidente Prudente que é muito mais definido por estar mais próximo. Da mesma forma, observa-se este efeito para o radar de Salesópolis quando comparamos com Bauru.

Para examinar os resultados das integrações, elaboramos uma comparação entre as distribuições de probabilidade de frequência do fator refletividade do radar obtidas pelas 2 metodologias propostas e com os CAPPIs de $3 \mathrm{~km}$ de altura calculados para os 3 radares meteorológicos durante o dia 4 de Fevereiro de 2003. Na Figura 13 é apresentado a distribuição relativa obtida pelos métodos de integração CAPPI e Volumétrica e os CAPPIs individuais, enquanto que na Figura 14 é apresentado a diferença do fator refletividade do radar observado pelos radares meteorológicos e os respectivos valores observados nos métodos de integração para a mesma probabilidade cumulativa.

A partir da Figura 13 é possível observar que para valores maiores que $35 \mathrm{dBZ}$ ambas integrações apresentam probabilidades ocorrência similares, entretanto para valores inferiores existe uma diferença. Por exemplo, a integração via CAPPI apresenta menores frequências de ocorrência entre 17 e $22 \mathrm{dBZ}$ e maior entre 23 e 35 dBZ. Já a volumétrica tem frequências maiores abaixo de $24 \mathrm{dBZ}$ e menores entre 24 e $35 \mathrm{dBZ}$.

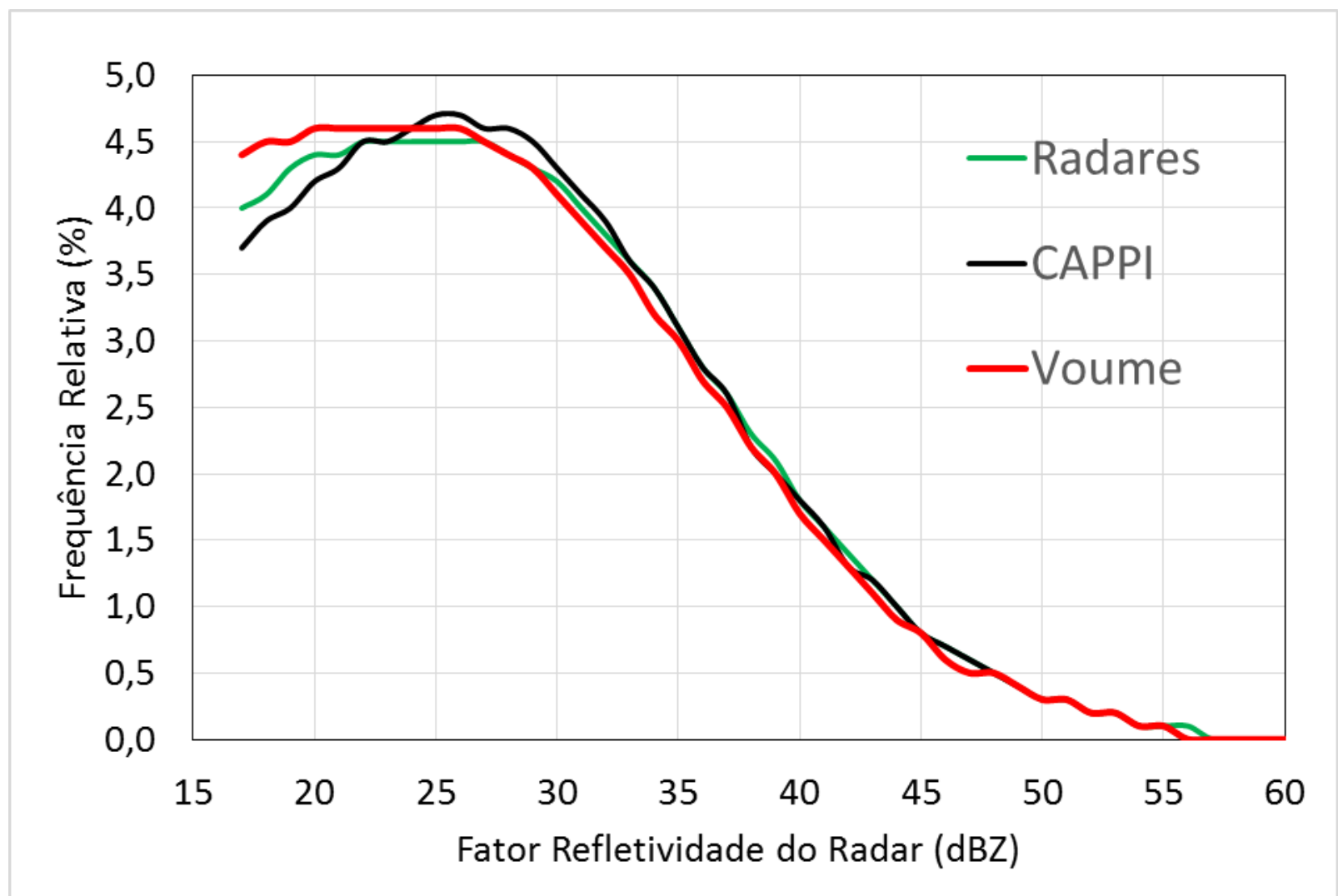

Figura 13 - Histograma de frequências de ocorrência de Ze combinando os 3 radares meteorológicos (linha verde) e a partir dos campos 3D da integração feita pelos métodos CAPPI (linha preta) e Volumétrica (vermelha)

Na Figura 14 este efeito é mais evidente e pode-se observar que o método
Volumétrico tende a apresentar refletividades menores $(<-0,5 \mathrm{dBZ})$ enquanto que o método 
de CAPPI superestima entre 17 e 29 dBZ até 0,2 dBZ e subestima até $-0,3 \mathrm{dBZ}$ para valores maiores que $29 \mathrm{dBZ}$. Apesar disso, como ambos as diferenças são inferiores a 0,5 dBZ, pode-se dizer que os métodos são satisfatórios em representar os campos de precipitação. As diferenças são inversas para valores de Zc inferior a $30 \mathrm{dBZ}$, e muito provavelmente deve estar associado às regiões de intersecção entre os radares, pois enquanto a integração volumétrica pondera pelo volume iluminado, o CAPPI o faz simplesmente pela distância. Logo, se o radar estiver mais próximo da grade ele deverá ter refletividade maior e assim uma maior contribuição. Por outro lado, a subestimativa da metodologia volumétrica traz um benefício pois independe de uma certa maneira do valor de refletividade do radar o que pode ser corrigido a partir de um offset, o que não é válido para o procedimento de integração via CAPPI. Portanto em termos de mosaico e posterior estimativa de precipitação a integração volumétrica se apresenta mais eficaz.

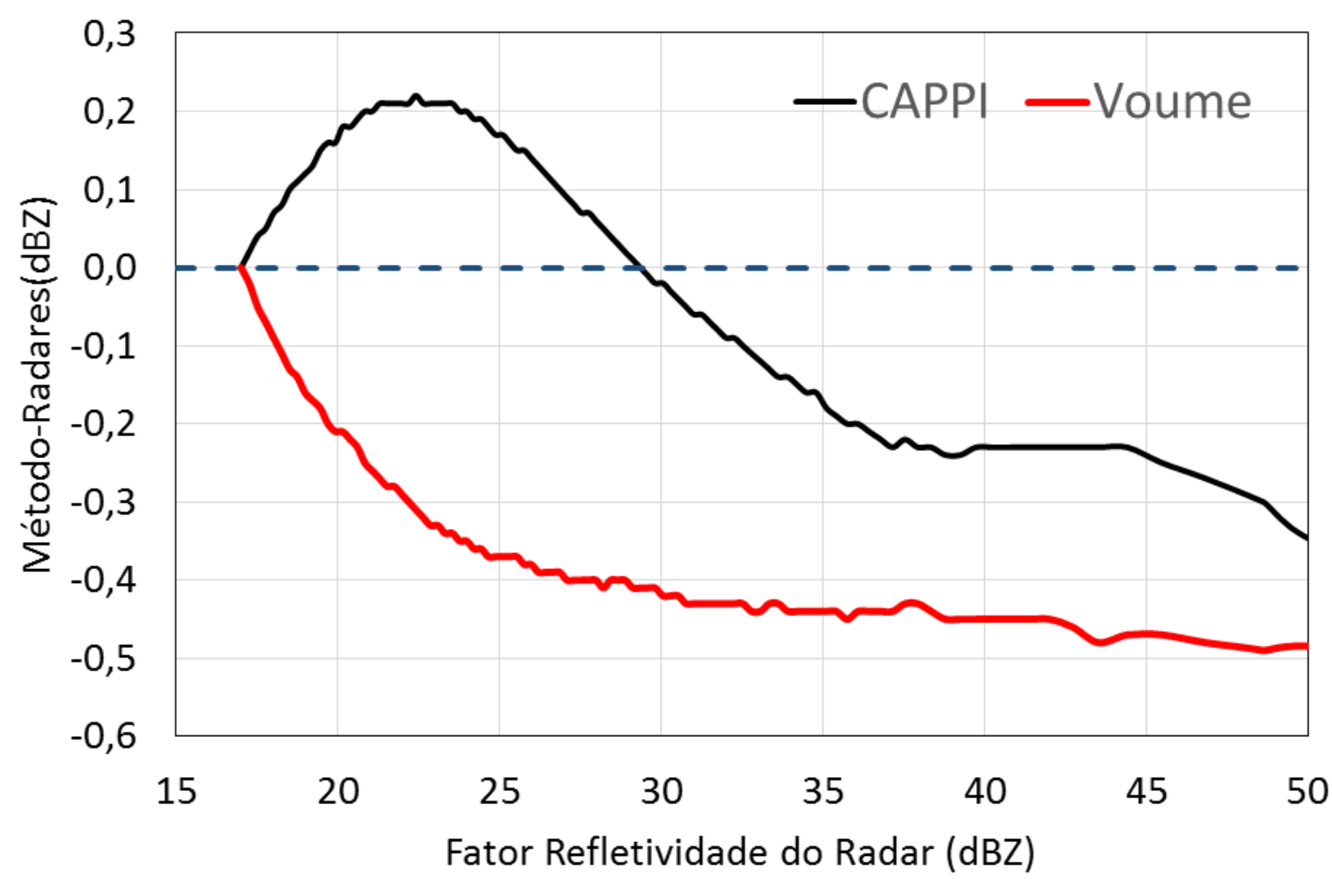

Figura 14 - Diferença do fator refletividade do radar (dBZ) para a mesma frequência cumulativa em função da refletividade do radar observada. CAPPI menos Radares meteorológicos (preta) e Volumétrico menos Radares meteorológicos (vermelha)

\section{CONCLUSÃO}

Este estudo apresentou uma metodologia para a integração de uma rede de radares meteorológicos, que contou com um procedimento de calibração e dois métodos de integração. O procedimento de calibração é extremamente necessário pois os radares meteorológicos possuem componentes eletrônicos que apresentam fadiga e desgaste com o tempo (válvula magnetron/klystron) ou mesmo sofrem ação do ambiente (antena e redoma), que levam a uma subestimativa da potência de retorno. Por outro lado, procedimentos inadequados de calibração ou mesmo medidas incorretas da potência transmitida podem criar um offset positivo ou negativo. Como um mosaico de precipitação 
requer uniformidade entre as medidas, qualquer offset nas observações pode proporcionar interpretações equivocadas, ou mesmo implicar em estimativas quantitativas de precipitação erradas.

A partir de uma análise com os dados do radar meteorológico do TRMM foi possível constatar que os 3 radares meteorológicos do estado de São Paulo apresentavam um bias, sendo que os radares meteorológicos de Salesópolis e Presidente Prudente superestimam o fator refletividade do radar em $+6,0$ e 4,4 dBZ respectivamente, enquanto que o radar de Bauru apresenta uma subestimativa de $-4,3 \mathrm{dBZ}$.

Finalmente na análise das metodologias de integração dos radares meteorológicos foi possível observar que a integração volumétrica, ou seja, a que leva em consideração a contribuição do volume iluminado, é mais eficiente e apresenta uma subestimativa de 0,5 dBZ, enquanto que apesar de ser mais simples, o procedimento via CAPPI apresenta tanto uma subestimativa como uma superestimativa em função do fator refletividade do radar o que pode comprometer a interpretação dos resultados ou mesmo na estimativa de precipitação.

\section{BIBLIOGRAFIA}

Anagnostou, E. N., and W. F. Krajewski, 1997: Simulation of radar reflectivity fields: Algorithm formulation and evaluation. Water

Resour. Res., 33, 1419-28.

Anagnostou, E. N., Morales, C. A., \& Calheiros, R. V. (2000). CALIBRATION OF GROUND WEATHER RADAR SYSTEMS FROM TRMM PRECIPITATION RADAR OBSERVATIONS: APPLICATION TO THE S-BAND RADAR IN BAURU, BRAZIL. In Congresso Brasileiro de Meteorologia, Rio de Janeiro-RJ, p. 1893_1898.

Anagnostou, E.N., C.A.Morales, T.Dinku, 2001: On the Use of TRMM Precipitation Radar Observations in Determining
Ground Radar Calibration Biases, Journal of Atmospheric and Oceanic Technology., 18, 616-628.

Awaka, J.; Iguchi, T.; Kumagai, H.; Okamoto K., 1997. Rain type classification algorithm for trmm precipitation radar. In: IEEE. Geoscience and Remote Sensing, 1997. IGARSS'97. Remote Sensing-A Scientific Vision for Sustainable Development IEEE International. v. 4, p. 1633-1635.

Costa, I., 2007. Avaliação dos dados produzidos pela rede de radares meteorológicos de banda" S" localizados no centro sul do Brasil, Tese de Mestrado, INPE, Cachoeira Paulista-SP.

Gekat, F.; Hille, M.; Niese, H.; Pool, M., "Accuracy of the engineering calibration of weather radars," Geoscience and Remote Sensing Symposium (IGARSS), 2010 IEEE International , vol., no., pp.1096,1099, 25-30 July 2010.

Gorgucci, E. R. Bechini, L. Baldini, R. Cremonini, and V. Chandrasekar, 2013: The Influence of Antenna Radome on Weather Radar Calibration and Its RealTime Assessment. J. Atmos. Oceanic Technol., 30, 676-689.

Iguchi, T.; Kozu, T.; Meneghini, R.; Awaka, J.; Okamoto, K. (2000), Rain-profiling algorithm for the trmm precipitation radar. Journal of Applied Meteorology, v. 39 , n. 12, p. 2038-2052.

Kawanishi, T., T. Kozu, R. Meneghini, J. Awaka, and K. Okamoto, 1998: Preliminary results of rain profiling with TRMM precipitation radar. Proc. SPIE: Microwave Remote Sensing of the Atmosphere and Environment, Beijing, China, International Society for Optical Engineering, 94-101.

Kummerow, C.; William Barnes, Toshiaki Kozu, James Shiue, and Joanne Simpson, 1998: The Tropical Rainfall Measuring 
Mission (TRMM) Sensor Package. J. Atmos. Oceanic Technol., 15, 809-817.

Morales, C.A.R., E.N. Anagnostou, 2003: Extending the capabilities of highfrequency rainfall estimation from geostationary-based satellite infrared via a network of long-range lightning observations, Journal of Hydrometeorology, V. 4, n๑ 2, pp. 141159.

Salazar-Cerreño, J.L., V. Chandrasekar, Jorge M. Trabal, Paul Siquera, Rafael Medina, Eric Knapp, and David J. McLaughlin, 2014: A Drop Size Distribution (DSD)Based Model for Evaluating the Performance of Wet Radomes for DualPolarized Radars. J. Atmos. Oceanic Technol., 31, 2409-2430.

Scarchilli, G., Gorgucci, E., Giuli, D., Baldini, L., Facheris, L., \& Palmisano, E. (1995). Weather radar calibration by means of the metallic sphere and multiparameter radar measurements. Il Nuovo Cimento C, 18(1), 57-70. 